\title{
PEDIGREE ANALYSIS AND POPULATION STRUCTURE OF BRAHMAN CATTLE FROM COSTA RICA
}

Marilyn Vásquez-Loaiza ${ }^{1}$, Argerie Cruz-Méndez ${ }^{2 a}$, Ruth Castro-Vásquez ${ }^{2 b}$, Susana Cascante-Segura ${ }^{3 a}$, Jorge Camacho-Sandoval ${ }^{3 b}$, Joel Domínguez-Viveros ${ }^{4 *}$

1 Asociación de Criadores de Ganado Cebú de Costa Rica. Calle Ismael Murillo 500, San José, Costa Rica https://orcid.org/0000-0002-7267-603X

${ }^{2 a}$ Instituto Nacional de Innovación y Transferencia en Tecnología Agropecuaria. AEA San Ramón. San Ramón, Alajuela, Costa Rica https://orcid.org/0000-0002-6603-4479

${ }^{2 b}$ Instituto Nacional de Innovación y Transferencia en Tecnología Agropecuaria. Mata Redonda, Avenidad 12 y Calle 88. San José, Costa Rica

https://orcid.org/0000-0002-2796-1536

${ }^{3 a}$ Corporación ganadera. El Prado Curridabat 11801, San José, Costa Rica

${ }^{3 b}$ Corporación ganadera. El Prado Curridabat 11801, San José, Costa Rica

https://orcid.org/0000-0001-5259-7468

${ }^{4}$ Facultad de Zootecnia y Ecología, Universidad Autónoma de Chihuahua. Km 1, Periférico Francisco R Almada, Chihuahua, Chihuahua, Mexico

https://orcid.org/0000-0002-4011-6142

*Corresponding author E-mail: jodominguez@uach.mx - joeldguezviveros@yahoo.com.mx

\section{ABSTRACT}

The objective of this study was to evaluate the population of Brahman cattle from Costa Rica. Pedigree analysis of 98,749 animals was used to estimate the following parameters: pedigree integrity, as a proportion of known ancestors; the number of complete generations, maximum generations traced, and equivalent complete generations; inbreeding coefficient (F); generation interval (GI) across four selection paths; additive genetic relationship (AGR); effective number of founders ( $f e$ ) and ancestors $(f a)$; and effective population size $(\mathrm{Ne})$. The analysis was carried out using the ENDOG software. The maximum proportions of unknown parents, grandparents, and great-grandparents were $14.1 \%, 38.9 \%$, and $61.2 \%$, respectively. Average $\mathrm{F}$ for the whole population was 0.86 , while $27.4 \%$ of the population was inbred, with an average $F$ of $3.1 \%$. The inbred population increased through the time, while $F$ decreased. The average AGR was 0.64 , with maximum values of 4.1 and positive trends. The $f e$ and $f a$ were 617.8 and 172.0, respectively. The Ne indicated increases of $\mathrm{F}$, with values lower than 1\%. The GI fluctuated from 6.4 to 7.4 , with an average of 6.85 years. These results summarize previous breeding practices and represent useful information for designing breeding programs by anticipating the relationship between the selection response and increases of inbreeding.

Key words: inbreeding, generation interval, effective population size, ancestors, zebu cattle.

\section{INTRODUCTION}

In Costa Rica, the populations of Zebu cattle (Bos indicus) trace back to 1911. Starting in 1946, the Costa Rican government initiated the genealogical recording (GR) of domestic cattle populations. In 1989, the government transferred the GR to the registration and specialized breeders' associations, which later gave birth to the Costa Rican Zebu (ASOCEBU) Cattle Breeders Association (Quirós, 2006; Vásquez-Loaiza and Molina-Castro, 2020). The ASOCEBU coordinates and controls the GR and production data of Zebu cattle populations under its administration. Additionally, this association oversees the development of breeding programs in accordance 
with the selection criteria and objectives for each breed of cattle (ASOCEBU, 2007; Camacho et al., 2019).

Pedigree records include the genealogical information of the entire population. Their main functions are to ensure breed purity, support conservation, and breeding programs, and provide a unique and permanent identification to each of the animals in the system. Pedigree analysis is used to: identify ancestors and founders, and their contributions $(\%)$ to variability; evaluate the levels of genetic variability; characterize the genealogical structure and demographics of a population; analyze the levels, trends, and possible effects of inbreeding. The population genetic parameters generated by pedigree analysis are of importance to implement conservation and / or genetic improvement programs (Melka et al., 2013; Cañas-Álvarez et al., 2014; Pereira et al., 2016; Santana et al., 2016; Chiara et al., 2019).

The genetic evaluations of Costa Rican Brahman cattle started in 2004 (Camacho and Cruz, 2004). The Best Linear Unbiased Prediction (BLUP), which results from the genetic evaluations, favors the selection of related animals, thus increasing inbreeding. Furthermore, inbreeding and kinship levels are involved in the process of genetic evaluations using BLUP (Santana et al., 2010; Pereira et al., 2016). Therefore, the objective of this study was to analyze the population structure of the Costa Rican Brahman cattle populations using pedigree analysis.

\section{MATERIALS AND METHODS}

This study analyzed the GR of Brahman cattle of Costa Rica. These records included information from 98,749 animals $(40.4 \%$ males and $59.6 \%$ females) born between 1965 and 2020, from 5,414 bulls and 29,880 mother cows, with an average of 16.2 and 2.8 calves, respectively. The analysis was carried out using the ENDOG software (Gutiérrez and Goyache, 2005). The population parameters used to analyze the structure and genetic variability were the following:

Pedigree integrity (Faria et al., 2009; Santana et al., 2016), as the proportion of known ancestors up to the fourth generation; the number of complete generations (NCG), maximum generations traced (NMGT), and equivalent complete generations (NECG).

Inbreeding coefficient $(\mathrm{F})$. The inbreeding coefficient of each individual was estimated, and its trend over birth years was generated (Falconer and Mackay, 1996; Parland et al., 2007).

Generation interval (GI). The GI was determined using the mean age of a reproductive animal, at which it is replaced by one of its offspring. The GI was calculated using the four selection paths: father - son, father - daughter, mother - son, and mother - daughter (RamírezValverde et al., 2018; Hagan and Cue, 2020).

Additive genetic relationship (AGR). The AGR was determined from the matrix of additive genetic relationships among all the individuals included in the pedigree. The calculation corresponds to the average value of the coefficients of each individual with the rest of the pedigree (Gutiérrez et al., 2003; Ocampo et al., 2020).

Effective number of founders $(f e)$. Founder, any animal with unknown parents. The $f e$ was defined as the founders that, by contributing in equal degree, would produce the existing genetic diversity in the population (Gutiérrez et al., 2009; Cañas-Álvarez et al., 2014).

Effective number of ancestors (fa). Ancestor, any animal, founder or not, that has contributed to the genetic variability of the population. The $f a$ was defined as the number of ancestors required to explain the total genetic variability of the population; it considers the genetic variability, which is not explained by the contribution of any of its offspring, provided by an animal (Gutiérrez et al., 2009; Cañas-Álvarez et al., 2014).

Effective population size (Ne). The Ne defines the number of breeding stock that could generate the calculated inbreeding and change rate in the genetic variance under the ideal population scheme; it was estimated through three different approaches: NCG, NMGT, and NECG (Gutiérrez et al., 2008; Leroy et al., 2013).

\section{RESULTS AND DISCUSSION}

Fig. 1 represents the proportion of known ancestors up to the fourth generation, where the maximum proportions of unknown parents, grandparents, and great-grandparents were $14.1 \%, 38.1 \%$, and $61.2 \%$, respectively. A total of 15,496 animals were identified as founders and 13,391 as ancestors, with $f a$ and $f e$ equal to 172.0 and 617.8 , respectively. The highest contributing ancestor explained $4.1 \%$ of the pedigree variability; 155 and 6,151 animals were responsible for $50 \%$ and $95 \%$ of the pedigree variability, respectively. The GR of Brahman cattle in Costa Rica requires at least three generations of known ancestors to issue a pure breed certificate (ASOCEBU, 2007); the proportion of individuals with unknown parents is attributed to the animals identified as founders. The precision and accuracy of a population structure analysis depend on pedigree integrity and the amount of genealogical information across generations. 


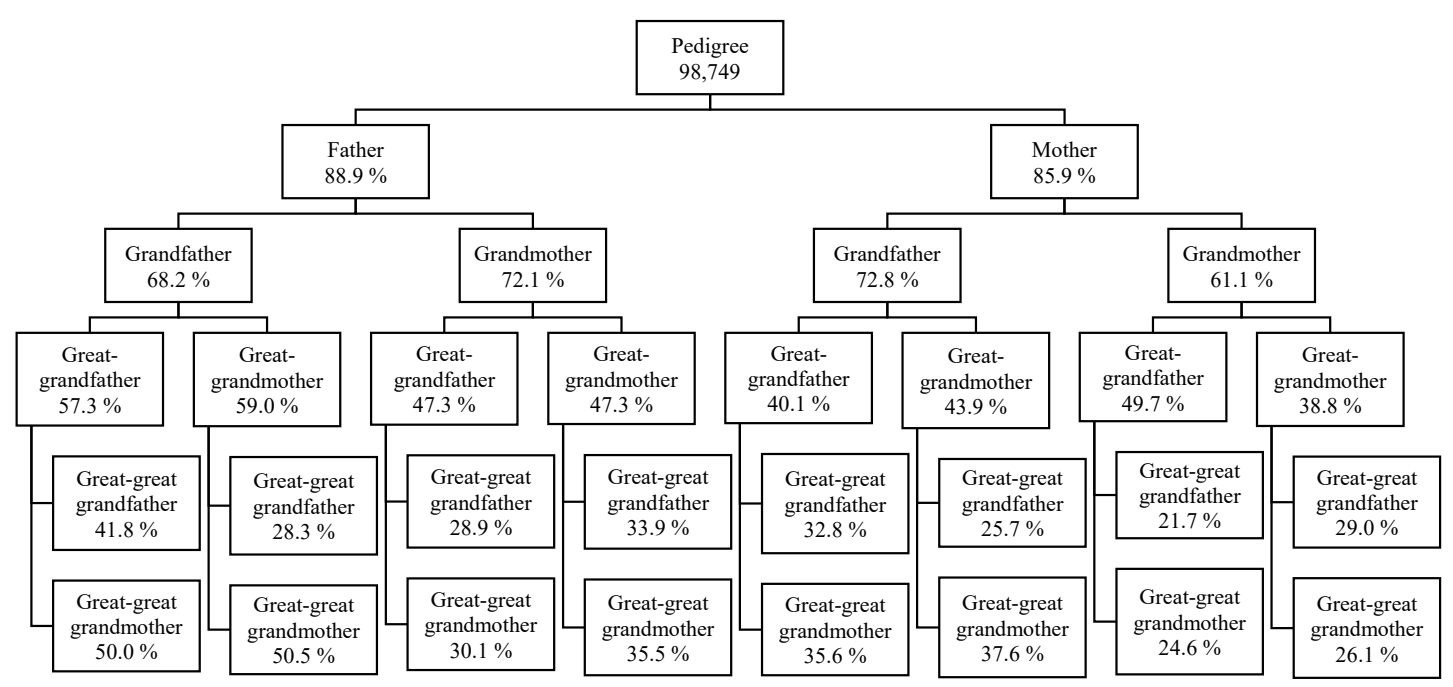

Fig. 1. Percentage of known ancestors in four generations of Brahman cattle.

Incomplete information results in an approximate generation assignment of individuals, and the calculations of $\mathrm{F}$ and $\mathrm{Ne}$ are imprecise.

Gutiérrez et al. (2003) evaluated eight Spanish breeds and reported lower pedigree integrity than that observed in the present study. In fact, the authors described that pedigree integrity was substantially lower (lower than 20\%) for the known ancestors of the second and third generations. However, our results are in agreement with Santana et al. (2012) and Abin et al. (2016), who evaluated two Brazilian and five South African breeds, respectively. Similarly, Ramírez-Valverde et al. (2018) conducted a study on seven Bos taurus breeds in Mexico and estimated pedigree integrity of similar magnitude. In Bos indicus breeds, Faria et al. (2009), Faria et al. (2010), Borges et al. (2013), Santana et al. (2014), and Costa et al. (2019) defined an interval for the proportion of known genealogical in the range of our results.

The average $\mathrm{F}$ for the total population was $0.86 \% ; 27.4 \%$ of the animals in the population were inbred, with an average of $3.1 \%$. Fig. 2 presents the proportion of inbred individuals and their inbreeding levels over time. This study observed contrasting trends; the proportion of inbred animals increased as the mean inbreeding coefficient decreased. Previous studies on Brahman cattle have reported $f a$ and $f e$ values ranging from 5.4 to 50 and from 5.4 to 718 , respectively. Additionally, average $\mathrm{F}$ values ranged from $0.69 \%$ to $11.9 \%$ (Faria et al., 2010; Santana et al., 2016; Cavani et al., 2018).

The AGR was 0.64 , with a maximum value of 4.1 and a positive trend over time (Fig. 3), which correlates with the behavior of the average inbreeding percentage shown in Fig. 2. The knowledge of the AGR allows the designing of breeding schemes while maintaining certain levels of $\mathrm{F}$ in the offspring. The results observed in Figures 2 and 3 can be attributed to the use of sires related to a large number of animals in the population; selection based on BLUP that increases the probability of selecting related animals; and advances in reproductive technologies that reduce the number of parents required to breed the next generation. In the relation of $f e$ and $f a$, the AGR indicates the percentage of the population that originated from a founder (Gutiérrez and Goyache, 2005).

The amount and trend of $F$, which depends on AGR and $\mathrm{Ne}$, represent the genetic variability evolution over time. Pedigree integrity is related to the NCG, NMGT, and NECG (Table 1), and the population structure results from the selection and breeding schemes adopted by the breeders. The genetic relationships between the founders and the $f e$ expose the initial genetic variability; the founders' contribution to pedigree variability exhibits the gene pool that has been maintained across generations (Biochard et al., 1997); a small number of ancestors that explain the pedigree variability is associated with increases in the levels of AGR and F. The $f a$ comprises the possible causes of loss in genetic variability. Generally, fe $>f a$, as this difference increases, the participation of founders decreases across generations; the fe / fa ratio shows differential breeding schemes and considers the possible bottlenecks experienced by the population. When this ratio is extended, it indicates that most of the ancestors were founders 


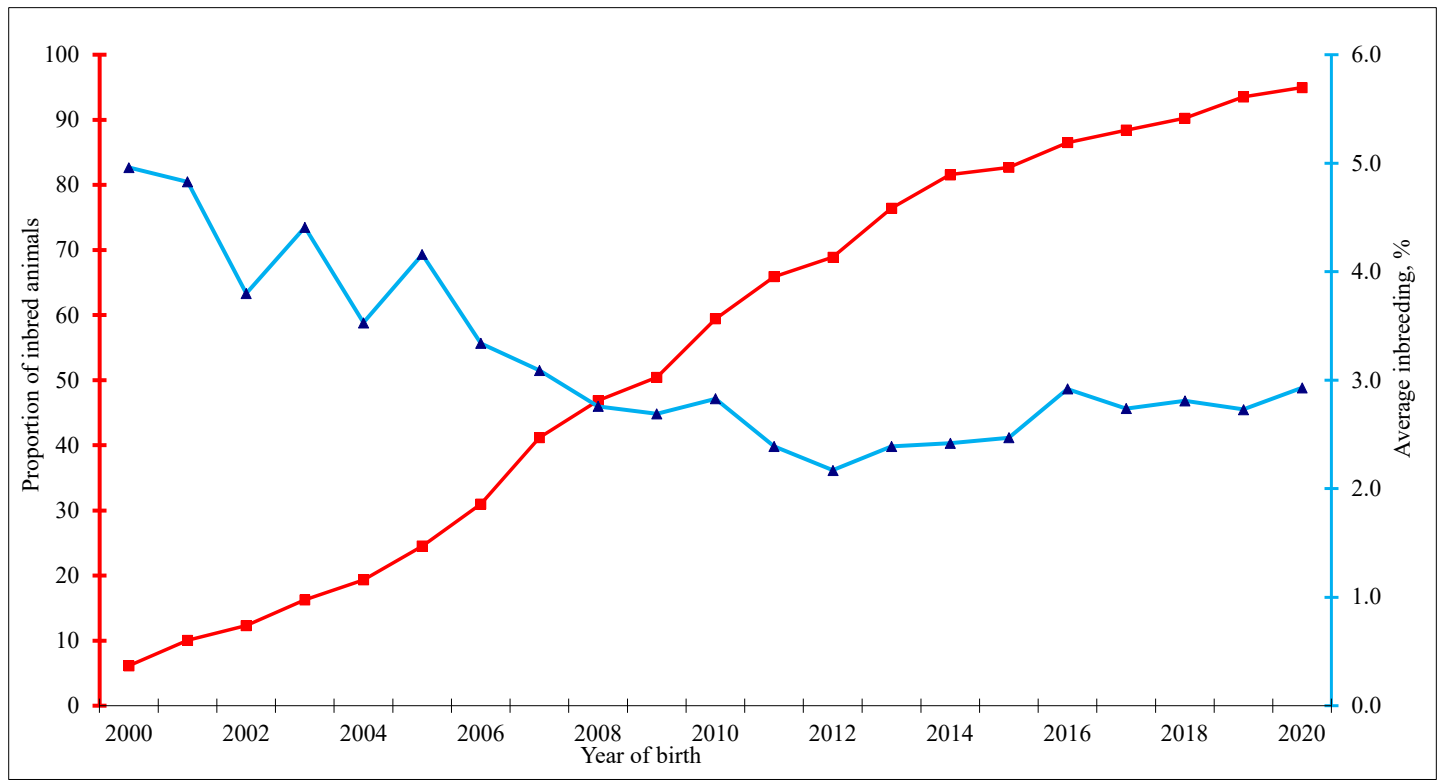

Fig. 2. Proportion of inbred animals and average inbreeding coefficient trends over year of birth.

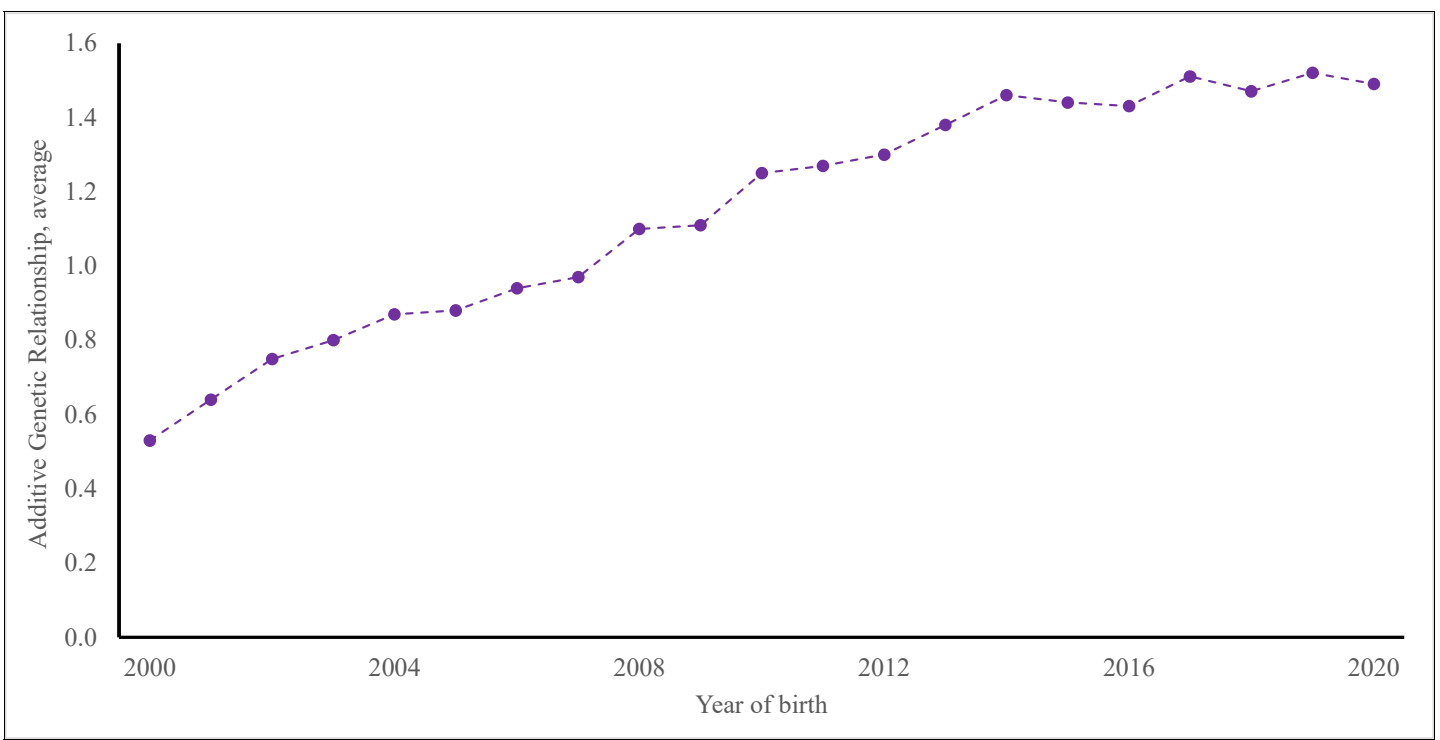

Fig. 3. Additive Genetic Relationship trends over year of birth.

with the absence of bottlenecks (Bernardes et al., 2016).

The Ne values in Table 1 indicate lower than $1 \%$ increases in $\mathrm{F}$. $\mathrm{Ne}$, as a concept, was developed based on ideal population guidelines. It reflects the accumulation of genetic relationships between individuals and allows predicting changes in the levels of F. A reduced $\mathrm{Ne}$ is associated with decreased genetic variability, increased mating between related individuals, allele fixation, and reduced selection response (Gutiérrez et al., 2009; Leroy et al., 2013). For the populations under breeding schemes, the recommended $\mathrm{Ne}$ values optimize the selection response with a minimum increase in F (Meuwissen et al., 1998).

The GI estimated using the four selection paths were (years \pm standar error): father - son 7.4 \pm 0.10 ; father - daughter $7.1 \pm 0.09$; mother - son 
Table 1. Number of generations and effective population size (Ne)

\begin{tabular}{lccc}
\hline & \multicolumn{3}{c}{ Number of generations } \\
\cline { 2 - 4 } Item & NCG & NMGT & NECG \\
\hline Max & 5 & 16 & 7.2 \\
Mean & 1.61 & 5.7 & 2.8 \\
$\Delta \mathrm{F} \%$ & 0.76 & 0.18 & 0.48 \\
Ne & 65.6 & 283.5 & 104.6 \\
\hline
\end{tabular}

Number of complete generations (NCG), maximum generations traced (NMGT), equivalent complete generations (NECG). Maximum (Max) and average (Mean) values. $\Delta \mathrm{F}$, inbreeding rate change. Ne, effective population size based on the number of known generations.

$6.5 \pm 0.08$; and, mother - daughter $6.4 \pm 0.07$. The magnitude of the GI can be associated with the production system, selection path, and market. In dairy cattle, Melka et al. (2013) reported, for five specialized breeds in Canada, GIs ranging from 3.64 to 6.63 years, with an average of 5.03 years. Hagan and Cue (2020) evaluated the behavior of the GI overtime in four specialized breeds. At the beginning, they observed GIs ranging from 4.5 to 12 years; after 25 years, the GIs ranged from 3.5 to 6.0 years. Previous studies in Brahman cattle have reported average GIs of 4.0 years (Cavani et al., 2018), ranging from 5.0 to 9.8 years (Santana et al., 2016). In dairy Gyr cattle, reported GIs are greater than 7 years, with maximum values of 12 years (Reis et al., 2010; Santana et al., 2014; Santana et al., 2016). In Nelore populations, the GI ranges from 6.5 to 10 years (Borges et al., 2013; Costa et al., 2019). In Bos taurus beef cattle breeds, previous studies have reported GIs ranging from 5.4 to 7.7 years (Parland et al., 2007), 4.9 to 8.2 years (Ramírez-Valverde et al., 2018), and average values between 6.0 and 6.4 years (Piccoli et al., 2014).

\section{CONCLUSIONS}

Based on the effective number, number of generations, and large proportion of known ancestors in the third and fourth generations, the evaluated pedigree presented an integral, complete, and deep structure. The results show a summary of the genetic and reproductive management that breeders have carried out, including levels of additive genetic relationship and indicating that the percentage of inbred animals has increased. However, the mean inbreeding value presented a negative trend and the forecasted increment, given the effective population size, is less than $1 \%$.

\section{ACKNOWLEDGMENTS}

We are grateful to the Costa Rican Asociación de Criadores de Ganado Cebú (ASOCEBU) for providing the evaluated database within the framework of the collaborative project on beef cattle breeding in Costa Rica.

\section{LITERATURE CITED}

Abin, S., H.E. Theron, and E. van Marle-Koster. 2016. Population structure and genetic trends for indigenous African beef cattle breeds in South Africa. South Africa J. Anim. Sci. 46:e2.

ASOCEBU. 2007. Reglamento para el registro genealógico de ganado de las razas cebuínas. Asociación de Criadores de Ganado Cebú de Costa Rica. San José, Costa Rica. Available from: http://asocebucr.com/ informacion/\#reglamentos. Accessed: August, 19, 2021.

Bernardes, P.A., D.A. Grossi, R.P. Savegnago, M.E. Buzanskas, S.B. Ramos, E.P. Romanzini, et al. 2016. Population structure of Tabapua beef cattle using pedigree analysis. Livest. Sci. 187:96-101.

Biochard, D., L. Maignel, and E. Verrier. 1997. The value of using probabilities of gene origin to measure genetic variability in a population. Genet. Sel. Evol. 29:5-23.

Borges, B.A.C., C.H. Mendes, P.L. Souza, L.M. Santos, D.P. Ambrosini, J.A. Carrillo, et al. 2013. Population structure of Nellore cattle in northeastern Brasil. Rev. Brasil. Zoot. 42:639644.

Camacho, S.J. y A. Cruz. 2004. Evaluación genética de sementales y hembras Brahman 2004/2005. Programa de evaluación y mejoramiento de bovinos de carne en Costa Rica. Corporación Ganadera, San José, Costa Rica. 
Camacho, S.J., A. Cruz, S. Cascante y N. Campos. 2019. Programa nacional de evaluación y mejoramiento genético de la raza Brahman. Sumario 2019. Corporación Ganadera. San José, Costa Rica.

Cañas-Álvarez, J.J., A. González-Rodríguez, D. Martín-Collado, C. Avilés, J. Altarriba, J.A. Baro, et al. 2014. Monitoring changes in the demographic and genealogical structure of the main Spanish local beef breeds. J. Anim. Sci. 92:4364-4374.

Cavani, L., R.M. de Oliveira, L.O. Duitama, R. Keith, T.S. Bertipaglia, M. Marques, et al. 2018. Genetic diversity of Brazilian Brahman cattle by pedigree analysis. Pesq. Agrop. Brasil. 53:74-79.

Chiara, F.M., M.P. Gonçalves, C. Dadousis, S. Biffani, R. Negrini, P.L. Souza, and R. Bozzi. 2019. Population structure and genetic diversity of Italian beef breeds as a tool for planning conservation and selection strategies. Animals. 9e880

Costa, D.J., A.J. da Silva, P.L. Souza, A.C. Muller y M.P. Gonçalves. 2019. Estrutura populacional e depressão endogâmica em características de crescimento de bovinos da raça Nelore criados no bioma Amazônia. Livest. Res. Rural Develop. 31e017

Falconer, D.S. y T.F.C. Mackay. 1996. Introducción a la genética cuantitativa. Editorial Acribia. Zaragoza, España.

Faria, F.J.C., A.E.V. Filho, F.E. Madalena, and L.A. Josahkian. 2009. Pedigree analysis in the Brazilian Zebu breeds. J. Anim. Breed. Genet. 126:148-153.

Faria, L.C., S.A. de Queiroz, P.A. Vozzi, R.B. Lobo, C.U. Magnaboso, and J.A. de Oliveira. 2010. Variabilidade genética de raça Brahman no Brasil detectada por meio de análise de pedigree. Pesq. Agropec. Bras. 45:1133-1140.

Gutiérrez, J.P., J. Altarriba, C. Diaz, R. Quintanilla, J. Cañon, and J. Piedrafita. 2003. Pedigree analysis of eight Spanish beef cattle breeds. Genet. Sel. Evol. 35:43-63.

Gutiérrez, J.P., and F. Goyache. 2005. A note on ENDOG: a computer program for analysis pedigree information. J. Anim. Breed. Genet. 122:172-176.

Gutiérrez, J.P., I. Cervantes, A. Molina, M. Varela, and F. Goyache. 2008. Individual increase in inbreeding allows estimating realized effective sizes from pedigrees. Genet. Sel. Evol. 40:359-378.

Gutiérrez, J.P., I. Cervantes, and F. Goyache. 2009. Improving the estimation of realized effective population sizes in farm animals. J. Anim. Breed. Genet. 126:327-332.
Hagan, B.A., and R. Cue. 2020. Generation intervals in Canadian dairy cattle herds. Can. J. Anim. Sci. 100:175-183.

Leroy, G., T. Mary-Huard, E. Verrier, S. Danvy, E. Charvolin, and C. Danchin-Burge. 2013. Methods to estimate effective population size using pedigree data: examples in dog, sheep, cattle, and horse. Genet. Sel. Evol. 45:1-10.

Melka, M.G., K. Stachowicz, F. Miglior, and F.S. Schenkel. 2013. Analyses of genetic diversity in five Canadian dairy breeds using pedigree data. J. Anim. Breed. Genet. 130:476-486.

Meuwissen, T.H.E., and A.K. Sonesson. 1998. Maximizing the response of selection with a predefined rate of inbreeding: overlapping generations. J. Anim. Sci. 76:2575-2583.

Ocampo, G.R., J. Ramírez, J. Lopera, G. Restrepo, and J. Gallego-Gil. 2020. Genetic diversity assessed by pedigree analysis in the Blanco Orejinegro (BON) cattle breed population from the Colombian germplasm bank. Chilean J. Agric. Anim. Sci. 36:69-77.

Parland, S.Mc., J.F. Kearney, M. Rath, and D.P. Berry. 2007. Inbreeding trends and pedigree analysis of Iris dairy and beef cattle populations. J. Anim. Sci. 85:322-331.

Pereira, R.J., M.L. Santana Jr, D.R. Ayres, A.B. Bignardi, G.R.O. Menezes, L.O.C. Silva, et al. 2016. Inbreeding depression in Zebu cattle traits. J. Anim. Breed. Genet. 133:523-533.

Piccoli, M.L., J. Braccini, F.V. Brito, L.T. Campos, C.D. Bértoli, G.S. Campos, et al. 2014. Origins and genetic diversity of British cattle breeds in Brazil assessed by pedigree analyses. J. Anim. Sci. 92:1920-1930.

Quirós, E. 2006. Historia de la ganadería bovina en Costa Rica. CORFOGA. San José, Costa Rica.

Ramírez-Valverde, R., A.R. Delgadillo-Zapata, J. Domínguez-Viveros, J.Á. Hidalgo-Moreno, R. Núñez-Domínguez, F.A. RodríguezAlmeida, et al. 2018. Pedigree analysis for determination of genetic diversity in Mexican beef cattle population. Rev. Mex. Cienc. Pecu. 9:614-635.

Reis, F.J.C., P. Sávio, R. da Silva, R. de Almeida, R. Luiz, and P.L. Souza. 2010. Population structure of Brazilian Gyr dairy cattle. Rev. Brasil. Zoot. 39:2640-2645.

Santana Jr, M.L., P.S. Oliveira, J.P. Eler, J.P. Gutiérrez, and J.B.S. Ferraz. 2012. Pedigree analysis and inbreeding depression on growth traits in Brazilian Marchigiana and Bonsmara breeds. J. Anim. Sci. 90:99-108. 
Santana Jr., M.L., P.S. Oliveira, V.B. Pedrosa, J.P. Eler, E. Groeneveld, and J.B.S. Ferraz. 2010. Effect of inbreeding on growth and reproductive traits of Nellore cattle in Brazil. Livest. Sci. 131:212-217.

Santana Jr, M.L., R.J. Pereira, A.B. Bignardi, D.R. Ayres, G.R.O. Menezes, and L.O.C. Silva, et al. 2016. Structure and genetic diversity of Brazilian Zebu breeds assessed by pedigree analysis. Livest. Sci. 187:6-15.

Santana Jr, M.L., R.J. Pereira, A.B. Bignardi, L. El Faro, H. Tonhati, and L.G. Albuquerque. 2014. History, structure, and genetic diversity of Brazilian Gir cattle. Livest. Sci. 163:26-33.

Vásquez-Loaiza, M. and R. Molina-Coto. 2020. Characterization of the Zebu cattle population with a certificate of genealogical registration in Costa Rica. Agron. Mesoamer. 31:679-694. 